\title{
"E o Verbo se fez carne": a Teoria dos Sistemas entre nós
}

LUHMANN, Niklas. Teoria dos Sistemas na Prática, v. II e III. Petrópolis: Rio de Janeiro, 2019 e 2020.

\section{Vinicius Madureira Maia* (1)}

\section{Resumo}

O texto apresenta e discute os dois últimos volumes de Teoria dos sistemas na prática, publicados pela Editora Vozes em 2019 e 2020, respectivamente. A trilogia foi editada a partir da seleção e tradução de nove estudos — igualmente distribuídos em cada edição - de um conjunto de vinte e seis trabalhos publicados por Niklas Luhmann ao longo, sobretudo, das décadas de 1980 e 1990. Voltados à análise detida de conceitos clássicos da tradição sociológica, os textos aí reunidos revelam a percepção epistemológica luhmanniana de que transformações das estruturas sociais - no caso, a transição da sociedade estamental do Antigo Regime para a sociedade moderna, sob a perspectiva de um primado da diferenciação funcional dos sistemas sociais - acarretam necessariamente transformações das estruturas semânticas. Em tese, tais implicações reclamam das ciências sociais uma teoria unificada e condizente com a sociedade moderna, acautelada contra a imposição de pregressas convenções conceituais.

Palavras-chave: Niklas Luhmann; teoria dos sistemas sociais; estrutura social; semântica.

* Universidade de São Paulo, São Paulo, SP, Brasil. 


\section{"And the Word was made flesh": the Systems Theory dwelt among us}

\section{Abstract}

The text presents and discusses the last two volumes of Teoria dos sistemas na prática, published in 2019 and 2020, respectively, by Vozes publishing house. The edition of this trilogy was based on the selection and translation of nine studies - which are equally distributed in each edition — out of a set of twenty-six works published by Niklas Luhman mostly over the course of the 1980s and 1990s. An anthology of sophisticated analysis of classical concepts of the sociological tradition, the texts gathered in Teoria dos sistemas na prática reveal the Luhmannian epistemological perception in the sense that the transformations of social structures - in this case, the transition from the stratified society of the Ancien Régime to the modern society, under the perspective of a functional differentiation of social systems' primacy necessarily entails transformations of the semantic structures. In principle, such implications demand from social sciences the construction of a unified theory, consistent with the modern society, which should be prevented against the imposition of previous conceptual conventions.

Keywords: Niklas Luhmann; theory of social systems; social structures; semantic.

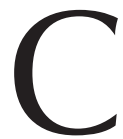

onstam, enfim, no catálogo da Coleção Sociologia da Editora Vozes, os dois últimos volumes de Teoria dos sistemas na prática — utilizo adiante a sigla TSP — , uma tríade cuidadosamente editada por Leopoldo Waizbort a partir da seleção e tradução de nove estudos, de um conjunto de vinte e seis trabalhos publicados por Niklas Luhmann ao longo, sobretudo, das décadas de 1980 e 1990, e agrupados sob o título Estrutura social e semântica: estudos em contribuição à sociologia do conhecimento da sociedade moderna (tradução livre). Do mesmo autor, a Vozes havia lançado, em 2016, o clássico Sistemas sociais: esboço de uma teoria geral, e, por conseguinte, em 2018, o primeiro volume de TSP,1 cujas edições já me parecem hábil e suficientemente comentadas por dois especialistas

${ }^{1}$ A Vozes também publicara, em 2009, um compilado de aulas ministradas por Luhmann (reunidas por Javier Torres Nafarrate), cá intitulado Introdução à Teoria dos Sistemas, do qual não parece haver, ao que consta, qualquer recensão até o momento. 
na obra desse sociólogo alemão, Stefan Klein (2017) e João Paulo Bachur (2018), respectivamente.

Os três volumes de TSP têm o condão de atenuar consideravelmente a defasagem da aparição das obras de Luhmann nos países de língua portuguesa; reunidos, eles dão conta do conteúdo por inteiro do Band 2 e, quase por completo, do Band 3 da aludida série Gesellschaftsstruktur und Semantik, publicada pela prestigiosa editora Suhrkamp. Tanto mais dignos de nota os seguintes fatos: (i) dois textos, "Sobre o conceito de classe social" e "Substituição da teoria na pedagogia: da filantropia ao neo-humanismo", são os primeiros a serem vertidos a outra língua além da original; (ii) à exceção dos dois primeiros estudos constantes nos volumes I e III, cada um dos demais escritos contemplados em toda a coletânea não havia logrado, até então, tradução para mais de duas outras línguas, segundo registros do Niklas Luhmann-Archiv, acomodado na Universidade de Bielefeld. Daí o acerto do entusiasmo de Bachur ao reconhecer: "há muito o que comemorar com a publicação" (2018, p. 1061).

Ora, no Brasil em especial, os principais trabalhos de Luhmann tardam a vir a lume ou surgem, quando menos, após a chegada e o estabelecimento da obra de seus críticos ou discípulos heterodoxos, como Habermas, Marcelo Neves, Günther Teubner, Fischer-Lescano, entre outros. Não à toa já se fale por aqui, ainda que em sentido mais amplo, em um "cenário pós-luhmanniano" (Ocampo; Brasil Jr., 2020). Tal contraste é, a um só tempo, causa e reflexo de uma recepção se não oblíqua, em todo caso intermitente e desordenada. Para se ter uma ideia, embora figure ao lado de Bourdieu como o sociólogo mundialmente mais expressivo desde a segunda metade do século XX, Luhmann não resta sequer vislumbrado em uma seleta de vinte e dois autores - considerados os principais da disciplina, "de Auguste Comte a Gilles Lipovesty" - recentemente organizada pela própria Editora Vozes.

Por outro lado, a idiossincrasia estilística de Luhmann tem engendrado dificuldades à compreensão geral de seus escritos, bem como consistido, talvez, no maior entrave à sua divulgação mundo afora. É tamanho o 
adensamento textual supostamente necessário para prevenir, segundo Luhmann, a imposição de tradições conceituais ou pré-conceitos estranhos a uma teoria unificada e condizente com a sociedade moderna, que salta aos olhos do leitor a impressão de ter diante de si uma espécie de dialeto, um novo Logos do pensamento sociológico. ${ }^{2}$ Se porventura chamou atenção a fórmula cristã empregada no título deste artigo, ela se deve a uma ilustrativa sugestão contida na apresentação de Leopoldo Waizbort — editor dos três volumes - ao volume I de TSP, a qual resume a contento o mote da coleção: abordar a teoria dos sistemas sociais por outro viés, "digamos pela via da história dos conceitos, dando carne e osso para os problemas e temas que na exposição da teoria enquanto tal aparecem muita vez de modo bastante abstrato - como por exemplo em Sistemas Sociais" (2018, p. 11). Pode-se supor que o próprio Luhmann, engajado como foi em um empreendimento catedralesco de construção conceitual, estaria de pleno acordo.

Os estudos seguintes [...] têm como eixo as transformações no mundo das ideias e dos conceitos que acompanham e sinalizam a passagem para a sociedade moderna [...] pressupõem um fundamento teórico transformado em relação à sociologia do conhecimento clássica. A atribuição de ideias aos grupos ou estratos que as sustentam é substituída por pressupostos bem mais complicados, referidos à teoria dos sistemas e à teoria da evolução. Nesse sentido, a pressuposição de que o desenvolvimento rumo ao moderno está conectado com a "ascensão da classe burguesa" é substituída pela tese: trata-se da passagem da diferenciação estratificatória da sociedade para a diferenciação funcional. [...] É requerida uma nova semântica e também um novo universalismo, que se adapte à diferenciação funcional e aos problemas de suas consequências (Luhmann, 2019, p. 15).

\footnotetext{
2 "A sugestão de originalidade absoluta é reforçada pela criação de uma teoria de linguagem acessível unicamente para 'iniciados'. E este caráter esotérico do jogo conceitual me parece constituir a segunda razão para a ampla atenção conferida a Luhmann." (Käsler, 1984, p. 188, tradução livre). Compare-se essa crítica ao seguinte trecho de Bourdieu, que participava de opinião assemelhada à de Luhmann (2002) quanto à aparência exotérica da sociologia, a qual seria necessariamente, na visão do primeiro, uma ciência esotérica: "a iniciação é lenta e requer uma autêntica conversão de toda uma visão do mundo" (Bourdieu, 2004, p. 70). Para Luhmann, aliás, a sociologia seria uma ciência latentemente religiosa, e Hegel - a quem Luhmann é frequentemente associado - concebia a filosofia, por sua vez, como uma espécie de culto contínuo.
} 
Razão pela qual os estudos compreendidos em TSP conformam verdadeiras contribuições à sociologia do conhecimento da sociedade moderna, como reza expressamente o subtítulo da série original. Pois, para o grande desespero dos homens, os cientistas sociais não têm o hábito, a cada vez que mudam as estruturas, de mudar de vocabulário: essa bem poderia ser uma paráfrase mordaz de Luhmann a propósito de um conhecido trecho de Marc Bloch. Afinal de contas, ele (Luhmann, 2016) não mostrava senão descontentamento com o assim considerado déficit teórico das ciências sociais no tocante à observação e descrição da sociedade moderna. Nutriu consigo a concepção de que a sociologia, na condição de mero empirismo, seria incapaz de explicar adequadamente a variedade onímoda da realidade social, bem como de compreender(-se em) uma teoria da sociedade tal como esta hoje se apresenta, isto é, acêntrica, hipercomplexa e policontextural, para utilizar aqui o jargão do luhmannês. E tal inépcia se deve, em parte, à ausência de percepção epistemológica de que as transformações das estruturas sociais acarretam necessariamente, visto acima, transformações das estruturas semânticas (Luhmann, 1997).

Em sua apresentação ao volume II de TSP, Waizbort (2019) propicia ao leitor, às expensas do próprio Luhmann, o oportuno resumo de um elenco - não taxativo - de quatro formas de diferenciação enquanto produtos da evolução da sociedade no plano da teoria dos sistemas, a saber: diferenciação segmentar, diferenciação segundo centro e periferia, diferenciação estratificatória e diferenciação funcional. Evolução social, digase de passagem, não significa aí "progresso" linear a formas supostamente melhores de diferenciação, uma vez que a teoria dos sistemas sociais não brande uma tábua de valores, tampouco se presta, conforme a prédica nietzscheana, à determinação de hierarquias axiológicas. Ademais, à guisa do desenvolvimento histórico no movimento dialético hegeliano, a evolução da sociedade se verifica quando uma forma de diferenciação se torna não supressiva, mas preponderante sobre as outras, ou, na linguagem de Luhmann, quando uma forma de diferenciação regula as aplicações possíveis das demais. Com efeito, a passagem do primado de uma forma de 
diferenciação à outra não implica exclusão da forma dominante precedente; diferentes formas de diferenciação amiúde coexistem. A título de ilustração, com a primazia da diferenciação funcional, pode-se ainda encontrar, normalmente, estratificação na figura de classes sociais, por exemplo, bem como diferenças segundo centro e periferia, as quais seriam, nada obstante, agora meros subprodutos da dinâmica própria dos sistemas funcionais (Luhmann, 1997; Waizbort, 2019).

No contexto de sua teoria dos sistemas sociais, a forma de diferenciação por estratos caracteriza uma modalidade de sociedade que predominou no âmbito europeu até o século XVIII, quando começou a ser substituída por uma forma de sociedade na qual a diferenciação funcional assumiu uma outra forma, de caráter funcional. Essa passagem da forma de diferenciação por estratos para a forma de diferenciação funcional detém especial importância, dado que assinala a transição para o mundo em que vivemos, a sociedade moderna. [...] O problema que nos interessa situa-se na passagem, no âmbito do processo de variação evolutiva da sociedade, da diferenciação estratificatória para a diferenciação funcional (Waizbort, 2019, p. 9 e 11).

Os tomos de TSP arrogam a exposição de tais transformações estruturais e suas implicações - "a obsolescência da semântica gestada na Velha Europa e a gestação de uma nova semântica" (Waizbort, 2019, p. 13) - a partir do exame detido de conceitos clássicos e caros à tradição sociológica, nomeadamente, ordem social, classe social, indivíduo, justiça, Estado, direito, religião, ética, moral, educação, humanismo etc. Luhmann pontificava que os hábitos de pensar europeus devem ser postos à prova de uma maneira muito mais decisiva do que havia sido feito até então, por exemplo, pelos próceres da Escola de Frankfurt, em cujas obras, ele denunciava, não seria possível encontrar em definitivo as respostas mais congruentes para as questões impingidas pela sociedade moderna funcionalmente diferenciada. Tinha clareza de que uma superteoria erigida conceitualmente a partir da sociedade hodierna seria algo muito mais radical e perturbador em suas consequências do que poderia jamais imaginar quem insistisse em recorrer 
a uma semântica inconsentânea e, tanto mais, empregada em meras críticas pontuais, máxime a crítica monocórdica do capitalismo (Luhmann, 1996).

Ciente do amplo consenso em vista do qual, desde o segundo terço do século passado, a sociologia veio a se reconhecer se reconhecer como ciência genuinamente empírica, Luhmann sustentava que a consciência metodológica sobre tal estatuto parece funcionar como uma sorte de garantia mesma da natureza científica da pesquisa sociológica. ${ }^{3}$ Chega-se, assim, a uma ciência social devotada à crença de que dados coletados apropriadamente conforme o método constituiriam uma espécie de comprovante por excelência da relevância das pesquisas empíricas para a realidade, cujos achados, a seu ver, o mais das vezes, não vão além dos ambientes que exploram, e cuja publicação serve eminentemente à popularização do respectivo ambiente explorado àqueles que porventura o ignorem - seja o entorno dos músicos amadores de Howard Becker ou a sociedade de esquina de Foote Whyte, por exemplo. Os cientistas sociais são naturalistas, zolistas; os sociólogos são mascates, vendendo imagens a prestação. Sob a perspectiva desse cânone metodológico, avaliações mais abstratas, calcadas em teoria, parecem indignas de consideração, ${ }^{4}$ lamenta (Luhmann, 1992). Um estado de coisas anterior à célebre crítica de Willard Quine ao positivismo lógico. Em tais circunstâncias, a sociologia não poderia, a rigor, dar respostas convincentes à pergunta: em que sociedade nós realmente vivemos hoje? Ou, mais ao gosto heideggeriano ${ }^{5}$ : será que hoje temos respostas para a pergunta sobre o que propriamente queremos dizer com a palavra "sociedade"? Será que hoje estamos em aporia por não a compreender?

\footnotetext{
${ }^{3}$ Em nota metodológica, já em 1957, Gilberto Freyre se declarava, cônscia e orgulhosamente, não adepto da sociologia "cientificista" de então, a qual, tão só "por basear-se em estatísticas e números, presume-se científica." (Freyre, 2004, p. 64).

${ }^{4}$ Querendo-se uma aproximação com as concepções de Adorno nesse sentido, cf. Cohn, 2008, p. 20-24 e o próprio Adorno, 2003.

${ }^{5} \mathrm{~A}$ propósito, Luhmann não seria ele também, nas palavras de Hannah Arendt, um tipo de rei abscôndito nos caminhos de floresta da sociologia?
} 
Nada obstante, prática "pretende indicar", no caso da antologia cá discutida, "um campo de investigação algo distinto da construção da teoria" (Waizbort, 2019, p. 9), o qual possui, por isso mesmo, uma peculiar motivação interna no âmbito da totalidade da obra luhmanniana. Logo, o termo não se entende como recurso a uma espécie de hipostatização, nem decerto se confunde com a "práxis" em sentido marxista. A teoria dos sistemas sociais de Luhmann não postula em absoluto uma décima primeira tese. Já é célebre - e controversa -, a esse respeito, a afirmação peremptória de que seu objetivo maior enquanto cientista social consistia na melhoria da descrição sociológica da sociedade e não na melhoria da sociedade em si. Empenhado em realizar uma abordagem sociológica decididamente distanciada da (militância) política, Luhmann defendia, um tanto irônico, que os cientistas sociais não podem estar em Bonn ${ }^{6}$ - ou em Brasília... - todo santo dia.

Feitas essas considerações, antes de adentrar os estudos de TSP propriamente ditos, vale ainda definir: estruturas sociais, em suma, são as condições que delimitam o escopo de relações das operações de um sistema social (política, economia, direito, arte etc.) ou, dito à moda de Luhmann, as condições da autopoiese do sistema. Semântica, por sua vez, consiste no patrimônio conceitual - cultura inclusa - da sociedade (Waizbort, 2018; Holmes, 2018).

O primeiro texto do volume II, "No início não havia injustiça", o qual conta com o filósofo Peter Sloterdjik entre os seus leitores mais entusiasmados, é um estudo "genial" sobre a origem da propriedade privada, que mostra, nas palavras de Bachur (2018, p. 1063), “como a transformação nas operações por meio das quais o solo podia ser apropriado ou dividido exigiu um conceito específico para isso."

Ato contínuo, em "Estado e razão de Estado na transição da dominação tradicional para a política moderna" Luhmann discorre, mediante um exercício de retrospectiva histórica, sobre como o conceito e a literatura sobre razão de Estado, emergentes ao cabo do século XVI, conferem

${ }^{6}$ Antiga capital administrativa da Alemanha, de 1949 até a reunificação em 1990. 
fortes indícios do surgimento de um novo tipo de compreensão do Estado. Os autores da temática da ragion di stato lograram contribuir (sem se aperceberem de tal transição, bem como desprovidos de uma conceituação então à altura) para a transposição do entendimento da prática do poder do âmbito da estratificação social para o da diferenciação funcional, ou seja, da dominação senhorial para a política no sentido moderno.

A edição encerra, então, com "Direitos subjetivos: sobre a restruturação da consciência jurídica para a sociedade moderna", que forma indiretamente com "Indivíduo, individualidade e individualismo" (este no v. I) um par estupendo. Ao remontar ao pano de fundo da tradição medieval do século XVI, Luhmann evidencia que, na reconstrução reflexiva da consciência jurídica para a sociedade moderna, opera-se uma transição da semântica precedente do ius - aquilo que é tido por justo em dada ordem objetiva, em cuja participação se atribuem aos indivíduos, proporcionalmente, direitos e deveres - à semântica de direitos concernentes a um sujeito, para os quais é desnecessária qualquer outra fundamentação.

Em se tratando do volume III de TSP, o texto "A diferenciação da religião", versa sobre o caso peculiar do processo histórico de diferenciação funcional do sistema da religião, outrora indistinta da sociedade, na forma de reação colateral [Nebeneffekt] à crescente diferenciação de outros sistemas funcionais - máxime a política, a ciência e a economia - internamente à sociedade e em relação à religião mesma. À medida que os sistemas sociais ganhavam paulatinamente autonomia em face dos vetustos controles do sistema da religião, a diferenciação deste transcorre, pois, não em curso evolutivo, mas involutivo; e a sociedade, ao seu turno, experiencia cada vez mais o fenômeno da secularização, traduzida não somente no esmaecimento gradual de uma mundividência teológica tradicional generalizadamente vinculante, mas também no relevo socioestrutural da "privatização" da decisão de cunho religioso. Equivale a dizer: a koinonia eclesiástica e a crença mesma tornam-se, então, questões de foro íntimo, particular, puramente. Isso posto, talvez caiba a seguinte indagação: a religião da moderna sociedade mundial seria, a rigor, um sistema autopoiético propriamente dito? 
Nesse sentido, em "Ética como teoria reflexiva da moral", Luhmann demonstra que, na sociedade estratificadamente diferenciada, a religião cristã consubstanciava a fonte única de que era então proveniente a semântica da moralidade, a qual se viu despojada de sua ancoragem social e religiosa a partir da transformação radical perpetrada pela diferenciação funcional dos sistemas - não à toa Luhmann se valha da locução Paradigm Lost noutro momento, em alusão à obra setecentista de John Milton, mais precisamente à metáfora da queda adâmica e à consequente transição do estado de inocência do homem e obediência a Deus. Urgiu, pois, o esforço filosófico destinado a fundamentar a moralidade, então, em si mesma; e é tão somente nos estertores do século XVIII que surge um novo tipo de ética, a qual busca fazer valer sua pretensão de se deparar como uma teoria reflexiva da moralidade, apta a responder, na versão da teoria dos sistemas sociais, às assim chamadas condições específicas da moral na sociedade moderna.

Por último, o estudo "Substituição da teoria na pedagogia: da filantropia ao neo-humanismo", que inaugura o volume III de TSP poderia talvez valerse da fórmula do título anterior, a saber, pedagogia como teoria reflexiva da educação. Nele, Luhmann reconstrói o curso histórico-científico através do qual o sistema da educação, no âmbito da pedagogia de cepa alemã, torna-se diferenciado em face das necessidades da divisão do trabalho e da nascente economia industrial, ao desenvolver a noção de Bildung [termo de difícil tradução: educação na forma de cultura, construção, cultivo de si] enquanto recurso de contingência, articulada pelo neo-humanismo ao longo do século XIX, principalmente, em substituição aos preceitos e finalidades educacionais do filantropismo, então referentes aos ditames da moralidade e da religião.

Como se vê, o modelo teórico (e histórico!) oferece instrumentos para pensar processos sociais variados e está longe de oferecer qualquer teleologia histórica ou teórica. Uma leitura atenta dos volumes de Teoria dos sistemas na prática, remontando o quebra-cabeças que os estudos apresentam ao serem tomados em conjunto, possibilita pôr à prova a ideia de correlação de estrutura social e 
semântica, assim como testar a tese da evolução das ideias e de um processo de mudança social característico da sociedade moderna, que Luhmann teve por bem denominar: diferenciação funcional, autorreferência, autodescrição, autopoiese (Waizbort, 2020, p. 11).

O movimento textual por entre os volumes de TSP é, pois, atrativo e deve despertar no leitor o interesse de se aventurar em experimentações intelectuais quejandas e estimulantes, como a de investigar, por exemplo, se teria ocorrido efetivamente uma passagem da sociedade moderna a uma aventada pós-modernidade; se esta última se trata, antes, de mera virada semântica (ou inflação discursiva?) desacompanhada de manifestas transformações estruturais. Das derradeiras análises do próprio Luhmann - cuja relação com os pensadores e conceitos ditos pós-modernos era ambivalente, diga-se de passagem - não advêm quaisquer evidências de que, em algum momento do século XX (desde a sua segunda metade em diante, presumivelmente), se tenha dado uma cesura epocal que pudesse justificar tal transição.

Como se vê da riqueza do material que se tem às mãos, é de se lamentar a ausência de um volume zero, por assim dizer, composto de textos extraídos do Band 1 da série original, cujos estudos não foram contemplados em nenhuma das edições de TSP, embora sejam, em tese, tão ou mais representativos da proposta cá editada, ${ }^{7}$ como se pode julgar a partir de alguns de seus títulos: "Estrutura social e tradição semântica", "Interação nos estratos superiores: da transformação de sua semântica nos séculos XVII e XVIII" ou "Temporalização da complexidade: da semântica dos conceitos de tempo da Época Moderna" (Waizbort, 2020, p. 15).

Igualmente sentida é a carência, em todas as três edições, de índices remissivos $^{8}$ e onomásticos, não necessariamente indispensáveis na hipótese de autores mais correntes ou cujas obras caiam mais no gosto de um grande

7 Vide, a propósito, o prefácio de Luhmann traduzido do volume original de 1980, que comparece didática e pertinentemente em todas as três edições de TSP; as apresentações de Waizbort a cada uma são, por sua vez, todas elas diversas e igualmente pedagógicas. ${ }^{8}$ Aliás, a aludida edição de Sistemas Sociais da Vozes dispõe de um glossário razoável (cf. Luhmann, 2016). 
público. No entanto, visto que TSP compreende excelentes amostras do pensamento heteróclito de Luhmann em sua quarta e última fase ${ }^{9}$ - repletas de referenciais teóricos frequentemente não sociológicos ou não canônicos, bem como de uma terminologia sabidamente abstrata, em parte oriunda de um processo laborioso de importação, apropriação, renomeação e ressemantização de conceitos firmados alhures, ou seja, no domínio das mais diversas ciências e modelos teoréticos -, aqueles índices seriam aqui, portanto, além de instrutivos, muito bem-vindos a título de consulta e controle dos atos tradutórios e das soluções adotadas.

Por fim, o leitor consciencioso de quaisquer volumes de TSP não perderá de vista algo aparentemente óbvio a essa altura: não se faz justiça à teoria dos sistemas sociais o render-lhe leituras ortodoxas. E, assim, ele talvez possa aqui e ali admitir que o paradigma teórico-sistêmico estabelecido por Luhmann, "demasiadamente impregnado pelo seu contexto de surgimento, isto é, pela experiência dos Estados na modernidade central" (Neves, 2015, p. 112-113), não logrou considerar originalmente que, em determinados sistemas funcionais de alguns Estados do "centro" e, sobretudo, da "periferia" da sociedade mundial, não se vislumbra, via de regra, "a correspondência funcional empírica entre problema (aumento de complexidade, crescente pressão por seleção) e solução de problema (especificação funcional, autonomia sistêmica)" (p. 132). Tal constatação teria validade no tocante, pelo menos, aos "sistemas jurídico e político, diferenciados segmentariamente em Estados. Em referência a esses sistemas, pode-se afirmar que o primado da diferenciação funcional é questionável" (p. 131). Disso, o caso da modernidade periférica não seria senão emblemático (Neves, [1992] 2018; Klein, 2017; em sentido crítico, Dutra, 2020). ${ }^{10}$

9 Sirvo-me aqui da catalogação intelectual proposta por um Bachur (2018) ciente da superposição ou simultaneidade de tais fases.

10 Não poucos autores - Karl Hondrich, Hans Haferkamp, Friedrich Tenbruck, Joachim Matthes, Franz-Xaver Kaufmann, Gerhard Wagner, Sérgio Costa, entre outros - puseram em xeque a articulação luhmanniana das formas de diferenciação no transcurso da evolução social, seja por sua alegada falta de suporte empírico e sua indeterminação histórica, seja por seu suposto apego ao parâmetro da modernização europeia. 
Informados do apreço de Luhmann por paradoxos, se é certo que a semântica deve refletir de forma adequada as estruturas sociais, podemos formular, nos termos de Deleuze e Spencer-Brown, que a potencialidade inerente à teoria dos sistemas sociais, sua radicalidade subjacente, é traída tão logo permaneçamos fiéis ao cerne de sua sociologia, isto é, se nos dedicarmos à sua mera atualização sem resposta à virtualidade correspondente; logo, tornamo-nos fiéis precisamente ao traí-la, ou seja, ao não repeti-la apenas, ao levar em consideração, se pretendemos melhor descrevê-la, o "espaço não marcado" das mais variadas assimetrias da sociedade mundial.

A própria teoria [além dos livros mesmos em que resta escrita] poderia também ser apresentada em outras sequências, e ela aguarda por leitores que contribuam com suficiente paciência, fantasia, habilidade e curiosidade para experimentar o que acontece com a teoria ao se tentar reescrevê-la de outro modo (Luhmann, 2018, p. 14-15).

À guisa de conclusão, Luhmann revelou, um dia, desejar para a sua ciência aquilo que um crítico literário húngaro, Miklós Szabolcsi, disse poder sentir aproximando-se da literatura, certa feita: "une nouvelle sévérité". Embora o título Teoria dos sistemas na prática possa insinuar facilidades a leitores mais afoitos ou desprevenidos - ou àqueles que, na opinião de um velho jurista, preferem "as apostilas aos livros", atribuindo tal capricho "a uma preguiça mental, a uma tendência a mastigar carne já moída" (Reale, 1977, p. VIII) -, a bem da verdade, com os nove estudos aí compreendidos, a sociologia deu um passo adiante, um passo vigoroso rumo a uma nova severidade, a uma nova disciplina do Espírito.

Vinícius Madureira Maia é graduado em Direito e doutorando no Programa de PósGraduação em Sociologia da Universidade de São Paulo (PPGS-USP).

$\triangle$ vi.madureira@gmail.com 


\section{Referências}

1. ADORNO, Theodor. A filosofia muda o mundo ao manter-se como teoria. Lua Nova, São Paulo, n. 60, p. 131-138, 2003.

2. BACHUR, João Paulo. A prática da teoria. Sociologia e Antropologia, v. 8, n.03, p. 1061-1066, 2018.

3. BOURDIEU, Pierre. Coisas ditas. São Paulo: Brasiliense, 2004.

4. CONH, Gabriel. Apresentação à edição brasileira: a sociologia como ciência impura. In: ADORNO, Theodor. Introdução à Sociologia. São Paulo: Editora UNESP, 2008. p. 19-40.

5. DUTRA, Roberto. Por uma sociologia sistêmica pós-colonial das diferenças no interior da sociedade moderna. Sociedade \& Estado, v. 35, n. 1, p. 259-280, jan.-/abr. 2020.

6. FREYRE, Gilberto. Ordem e progresso. São Paulo: Global Editora, 2004.

7. HOLMES, Pablo. A semântica da complexidade e sua estrutura social: o materialismo "pós-estruturalista" da teoria dos sistemas. Sociologias, Porto Alegre, v. 20, n. 47, p. 338-368, jan.-/abr. 2018.

8. KÄSLER, Dick. Flug über den Wolken. Der Spiegel, n. 50, p. 184-190, 1984.

9. KLEIN, Stefan. Niklas Luhmann, Sistemas sociais: esboço de uma teoria geral. Tempo Social, v. 29, n. 3, p. 349-367, 2017.

10. LUHMANN, Niklas. Teoria dos sistemas na prática. v. III (História, semântica e sociedade). (Ed. Leopoldo Waizbort). Petrópolis: Vozes, 2020.

11. LUHMANN, Niklas. Teoria dos sistemas na prática. v. II (Diferencial funcional e modernidade). (Ed. Leopoldo Waizbort). Petrópolis: Vozes, 2019.

12. LUHMANN, Niklas. Teoria dos sistemas na prática. v. I (Estrutura social e semântica) (Ed. Leopoldo Waizbort). Petrópolis: Vozes, 2018.

13. LUHMANN, Niklas. Sistemas sociais: esboço de uma teoria geral. Petrópolis: Vozes, 2016.

14. LUHMANN, Niklas. Ciência incompreensível: problemas de uma linguagem própria à teoria. Novos Estudos CEBRAP, n. 63, p. 51-59, 2002.

15. LUHMANN, Niklas. Die Gesellschaft der Gesellschaft. v. II. Frankfurt am Main: Suhrkamp Taschenbuch Verlag, 1997.

16. LUHMANN, Niklas. Protest: Systemtheorie und soziale Bewegungen. (Ed. Kai-Uwe Hellmann). Frankfurt am Main: Suhrkamp, 1996.

17. LUHMANN, Niklas. Probleme in der Forschung der Soziologie. In: LUHMANN, Niklas. Universität als Milieu (Ed. André Kieserling). Bielefeld: Haux, 1992. p. 69-73. 
18. NEVES, Marcelo. Constituição e direito na modernidade periférica: uma abordagem teórica e uma interpretação do caso brasileiro. São Paulo: WMF Martins Fontes, 2018.

19. NEVES, Marcelo. Os Estados no centro e os Estados na periferia: alguns problemas com a concepção de Estados da sociedade mundial em Niklas Luhmann. Revista de Informação Legislativa, v. 52, n. 206, p. 111-136, 2015.

20. OCAMPO, Sérgio P.; BRASIL Jr., Antonio. O cenário "pós-luhmanniano" e a América Latina: entrevistas com Marcelo Neves e Aldo Mascareño. Sociologia \& Antropologia, v. 10, n. 1, p. 15-72, 2020.

21. REALE, Miguel. Lições preliminares de Direito. São Paulo: Saraiva, 1977.

22. WAIZBORT, Leopoldo. Apresentação. In: LUHMANN, Niklas. Teoria dos sistemas na prática. v. I (Estrutura social e semântica) (Ed. Leopoldo Waizbort). Petrópolis: Vozes, 2018. p. 9-11.

23. WAIZBORT, Leopoldo. Apresentação. In: LUHMANN, Niklas. Teoria dos sistemas na prática. v. II. (Diferencial funcional e modernidade). (Ed. Leopoldo Waizbort). Petrópolis: Vozes, 2019. p. 9-13.

24. WAIZBORT, Leopoldo. Apresentação. In: LUHMANN, Niklas. Teoria dos sistemas na prática. v. III (História, semântica e sociedade) (Ed. Leopoldo Waizbort). Petrópolis: Vozes, 2020. p. 9-13.

Submetido em: 9 de julho de 2020

Aceito em: 9 de setembro de 2020 